
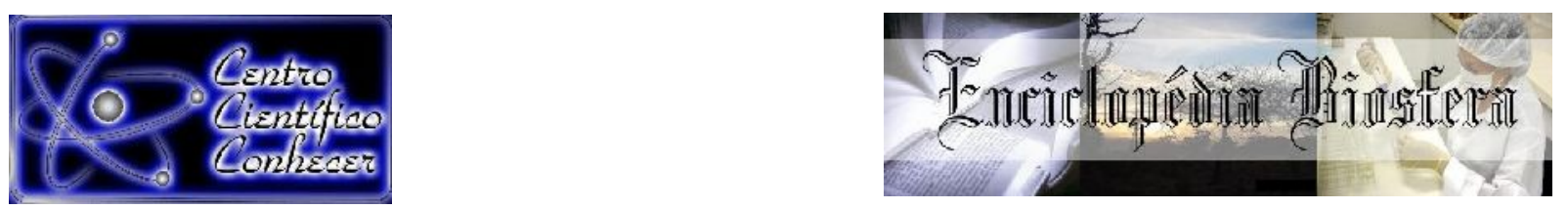

\title{
DOENÇAS DE NOTIFICAÇÃO OBRIGATÓRIA DE RELEVÂNCIA EM EQUÍDEOS NO BRASIL
}

\author{
Lara Reis Gomes ${ }^{1}$, Gabriela Ribeiro da Silva ${ }^{2}$, Ana Laura Martins Ferreira ${ }^{3}$ \\ ${ }^{1}$ Doutoranda em Medicina Veterinária da Universidade Federal de Uberlândia (UFU), \\ Uberlândia-MG, Brasil \\ ${ }^{2}$ Bacharel em Medicina Veterinária da Universidade Federal de Uberlândia (UFU), \\ Uberlândia-MG, Brasil- Email: gabirs.05@gmail.com \\ ${ }^{3}$ Graduanda em Medicina Veterinária da Universidade Federal de Uberlândia (UFU), \\ Uberlândia-MG, Brasil
}

Recebido em: 15/02/2021 - Aprovado em: 15/03/2021 - Publicado em: 30/03/2021

DOI: 10.18677/EnciBio_2021A7

\begin{abstract}
RESUMO
Anemia infecciosa equina, influenza equina, mormo, encefalomielite equina do leste e encefalomielite equina do oeste são doenças que exigem notificação obrigatória ao Serviço Veterinário Oficial do Brasil quando houver qualquer caso suspeito de acordo com a Organização Mundial de Saúde Animal (OIE). Medidas como estas são necessárias para a manutenção da qualidade sanitária do plantel visto que atualmente a equideocultura ganha destaque não apenas como força no trabalho do campo, mas também em áreas como lazer, terapias e esporte, estreitando ainda mais seu contato com o ser humano, o que representa mais um ponto relevante especialmente devido ao fato de que o mormo e as encefalomielites são consideradas doenças zoonóticas. Além disso, tais enfermidades são altamente contagiosas e se espalham com facilidade entre os indivíduos, principalmente aqueles que vivem em haras e participam de eventos equestres. Diante deste fato, torna-se importante ressaltar que tais enfermidades causam grandes prejuízos econômicos aos criadores, principalmente em se tratando de doenças que não possuem vacinas e tratamento como é o caso da anemia infecciosa equina, na qual, os animais positivos para a doença devem ser eutanasiados. Portanto o presente trabalho visa apontar os principais aspectos das doenças frequentemente relatadas de maior incidência no Brasil, bem como a epidemiologia das mesmas atualmente.
\end{abstract}

PALAVRAS-CHAVE: Enfermidades, equideocultura, eutanásia.

\section{MANDATORY RELEVANCE NOTIFICATION DISEASES IN EQUIDES IN BRAZIL}

\begin{abstract}
Infectious equine anemia, equine influenza, glanders, equine encephalomyelitis of the east and equine encephalomyelitis of the west are diseases that require mandatory notification to the Official Veterinary Service of Brazil when there is any suspected case according to the World Organization for Animal Health (OIE). Measures such as these
\end{abstract}


are necessary to maintain the health quality of the squad since currently equideoculture is gaining prominence not only as a force in field work, but also in areas such as leisure, therapies and sport, further strengthening its contact with human beings, which represents another relevant point, especially due to the fact that glanders and encephalomyelitis are considered zoonotic diseases. In addition, these diseases are highly contagious and spread easily among individuals, especially those who live in farms and participate in equestrian events. In view of this fact, it is important to emphasize that such diseases cause great economic damage to breeders, especially in the case of diseases where vaccines and treatment do not yet exist, such as equine infectious anemia, in which animals positive for the disease Therefore, the present work aims to point out the main aspects of the most frequently reported diseases in Brazil, as well as their epidemiology today.

KEYWORDS: Diseases, equine culture, euthanasia.

\section{INTRODUÇÃO}

De acordo com estudos realizados pela escola Superior de Agricultura Luiz de Queiroz da Universidade de São Paulo (Esalq/SP) em 2017, o Brasil possui o terceiro rebanho mundial de equinos, estimado em cerca de 5,8 milhões de animais, mostrando de forma expressiva sua contribuição para a economia brasileira, além disso, o estudo também aponta uma movimentação de aproximadamente $\mathrm{R} \$ 16,5$ bilhões, e geração de empregos diretos e indiretos (CILO, 2019). Com o aumento progressivo da produção de equinos, observa-se também uma intensificação no sistema, o que consequentemente leva a um aumento da proliferação de doenças infectocontagiosas, pois animais passam a viver em regime de confinamento (KETTLE, WERNERY, 2016).

Conforme relatos da Organização Mundial de Saúde Animal (OIE), e também de acordo com levantamentos epidemiológicos realizados no Brasil, doenças como a anemia infecciosa equina, influenza equina, mormo e as encefalomielites equina do leste, oeste e venezuelana, são consideradas doenças de notificação obrigatória (OIE, 2017).

A obrigatoriedade de notificação ao Serviço Veterinário Oficial do Brasil destas enfermidades se deve principalmente ao fato de que, algumas destas doenças não possuem vacinação contra seu agente etiológico como, por exemplo, a anemia infecciosa equina e o mormo que também não possuem tratamento eficaz. Além disso, se disseminam com facilidade pelo plantel (OIE, 2017). Outro motivo pelo qual estas doenças devem ser notificadas se deve ao fato de algumas terem potencial zoonótico com é o caso do mormo, das encefalomielites e da influenza equina, colocando em risco a vida de quem tem contato direto com estes animais (OIE, 2017).

Assim sendo, o objetivo deste trabalho consiste em apontar, a partir de uma revisão de literatura, as principais doenças infectocontagiosas que mais acometem equídeos no Brasil, bem como as medidas que devem ser adotadas mediante o diagnóstico das mesmas, além do seu impacto para a cadeia produtiva.

\section{Anemia Infecciosa Equina (AIE)}

A anemia infecciosa equina (AIE) trata-se de uma das doenças mais importantes da equideocultura brasileira, em especial por ainda não possuir vacinas e tratamentos eficazes devido às alterações constantes no material genético do vírus (SILVA et al., 
2016). A enfermidade é causada pelo Equine Infectious Anemia Virus (EIAV), um retrovírus, pertencente à família Retroviridae, gênero Lentivirus, que acomete equídeos de todo o mundo (RICOTTI et al., 2016), sendo mais identificada em regiões úmidas e montanhosas de clima tropical e subtropical, onde existe grande quantidade de vetores, daí o motivo pelo qual é conhecida popularmente como febre dos pântanos (RAVAZZOLO; COSTA, 2017).

A principal forma de transmissão ocorre a partir da picada de insetos hematófagos (forma mecânica) como as moscas do gênero Tabanus spp. (mosca do cavalo) e Stomoxys calcitrans (mosca dos estábulos), responsáveis por transmitirem sangue infectado com o vírus de animais doentes para animais saudáveis (NOGUEIRA et al., 2017).

Outra forma de transmissão consiste no uso compartilhado de fômites (cabrestos, esporas, material de casquear, agulhas descartáveis e material cirúrgico) contaminados (forma iatrogênica), e vem sendo associado à identificação de novos surtos da doença em locais onde a ocorrência encontrava-se baixa, podendo estar relacionada a hábitos inadequados de biossegurança no manejo dos animais (OLIVEIRA et al., 2017). De forma menos comum, mas não menos importante, a transmissão também pode ocorrer através da ingestão de colostro, via intrauterina (transmissão vertical) e sêmen (ISSEL; FOIL 1984; NOGUEIRA et al., 2017).

Após o animal ser infectado, o EIAV tem como alvo principal células como os monócitos/macrófagos, e maior carga viral poderá ser encontrada comumente nos tecidos hepático, pulmonar, renal e esplênico, além de já ter sido encontrado também na medula óssea, linfonodos e monócitos circulantes. A replicação viral nestes tecidos é responsável por lesões teciduais e consequentemente a manifestação dos sinais clínicos, destacando-se a observação de hepatomegalia e esplenomegalia (CRAIGO; MONTELARO, 2008).

O sinal clínico mais observado da enfermidade consiste em anemia decorrente de dois fatores, sendo: a hemólise imunomediada e a depressão da atividade medular, fator diretamente ligado à multiplicação viral. Associada a este quadro observa-se também trombocitopenia, que embora esteja caracterizando um sinal inicial da doença, pode ser identificado em quase todos os casos, aparentemente devido aos fatores como TNF- $\alpha$, TNF- $\beta$ e IL-6, produzidos por macrófagos infectados com o vírus. Estes fatores poderão atuar na depleção plaquetária inibindo 0 crescimento dos megacariócitos (RAVAZZOLO; COSTA, 2017), além de induzir a quadros de febre e também interferindo negativamente na eritropoiese, o que leva ao estado de anemia (LEROUX; COOK, 2016).

A infecção pelo EAIV é por toda a vida do animal, e a manifestação clínica da doença vai variar entre os indivíduos de acordo com a carga viral e a virulência da cepa infectante (RAVAZZOLO; COSTA, 2017). No que diz respeito ao curso clínico da doença, este pode se apresentar de três formas: agudo, crônico e subclínico. $\mathrm{Na}$ manifestação aguda da doença, que pode acontecer de 7 a 30 dias após a infecção, os principais sinais clínicos apresentados consistem em picos elevados de febre com alterações hematológicas (anemia, trombocitopenia), letargia e diminuição do apetite. Porém, os animais podem não apresentar tais sinais clínicos ou os mesmos podem estar limitados apenas a sintomas febris leves. Em casos mais graves, o animal pode desenvolver petéquias, anemia hemolítica e epistaxe. Já na forma crônica, os sinais 
clínicos podem se desenvolver em até 12 meses após a infecção. O animal infectado irá manifestar quadros de viremia recorrente e ciclos de anemia, além de depressão, emagrecimento progressivo, edema nos membros inferiores, trombocitopenia e até mesmo distúrbios neurológicos como ataxias ou encefalites, embora estes sejam mais raros. O estágio inaparente da doença ocorre mediante a diminuição da viremia com o decorrer do tempo, sendo de difícil detecção, pois neste estágio, a replicação do EAIV ocorrerá apenas no interior dos macrófagos. Em se tratando da forma subclínica da doença, a mesma é representada por aqueles animais que de início são apenas portadores, ou seja, não apresentam sinais clínicos visíveis, podendo tornar-se doentes mediante situações de estresse ou em associação a outras doenças, devido à queda na imunidade (ISSEL; FOIL, 1984; MONTELARO et al., 1993; SELLON, 1993; OAKS et al., 1998; HARROLD et al., 2000; DONG et al., 2013; ISSEL et al., 2014; RAVAZZOLO; COSTA, 2017).

Considerando a importância econômica e social da equideocultura, o diagnóstico laboratorial é de fundamental importância para detecção dos portadores da doença e identificação das propriedades acometidas pelo EAIV e monitoramento de possíveis surtos da doença (SILVA et al., 2016).

Como método oficial para diagnosticar a AIE, utiliza-se o teste de Coggins, também conhecido como Imunodifusão em Gel de Ágar (IDGA), responsável pela detecção de anticorpos anti-p26 (OIE, 2019). Apesar do teste ser mundialmente conhecido pela sua especificidade e estar relacionado à presença do vírus no organismo do animal, é considerado um teste pouco sensível, o que pode levar ao aumento de diagnósticos falso-negativos (NAVES et al., 2018). Assim sendo, e seguindo o exemplo de outros países, em 2018 o Ministério da Agricultura, Pecuária e Abastecimento (MAPA) instituiu a Instrução Normativa 52 que prevê a autorização do uso de Ensaios de Imunoabsorção Enzimáticas (ELISAs) para diagnóstico da enfermidade (BRASIL, 2018a) devido a maior sensibilidade do ELISA em relação IDGA (NAVES et al., 2018).

Deve-se ressaltar que, o teste de ELISA deverá ser realizado apenas como triagem, e que todas as amostras positivas devem passar pelo teste de IDGA, e em casos onde houver divergência nos resultados entre os dois métodos, o resultado final obtido pelo teste de IDGA é o que deve permanecer (CURSINO et al., 2018).

É bastante importante o diagnóstico laboratorial necessário para controle e prevenção da doença, pois, ainda não existe a disponibilidade de vacinas e tratamentos para aqueles indivíduos diagnosticados com a AIE, as medidas de controle e profilaxia de acordo com as condições epidemiológicas de cada Unidade da Federação (UF), avaliadas pelo serviço veterinário. No entanto, as ações contra a doença são realizadas com base em medidas gerais como, por exemplo, realização de exames preventivos para monitoramento de propriedades, controle de vetores, higienização correta de fômites, uso e descarte adequado de materiais descartáveis (agulhas, seringas), controle do trânsito de animais, além da eutanásia de animais positivos no teste de IDGA. Ainda de acordo com a legislação vigente, outras medidas que podem ser adotadas consistem na interdição da propriedade onde estes animais foram diagnosticados com o EIAV, sua identificação e isolamento até que seja realizada a eutanásia, e a liberação da propriedade somente ocorrerá após a realização de dois exames consecutivos com resultados negativos em todos os equídeos do plantel, em 
um intervalo de 30 a 60 dias (BRASIL, 2009).

De acordo com o MAPA (Ministério da Agricultura, Pecuária e Abastecimento), em 2017 até o mês de julho, houveram 2.303 casos confirmados de AIE no Brasil, número bastante significativo em relação à população de equinos. Vários são os estudos sobre a prevalência de AIE, porém a prevalência é bastante variada dependendo do perfil zootécnico estudado e da região estudada (ALMEIDA et al., 2017; CUTOLO et al., 2014).

Silva e colaboradores (2016) observaram ampla distribuição geográfica da AIE no Brasil, com variação nas taxas de prevalência desta enfermidade. Em seis anos de pesquisa sobre a prevalência de AIE em municípios do meio-norte mato-grossense, verificaram tendência de redução com o passar dos anos $(3,76 \% ; 4,26 \% ; 2,89 \%$; $3,11 \% ; 2,89 \%$ e $2,40 \%$ ), devido ao monitoramento realizado nos animais, bem como a realização periódica de exames, que permitem a adoção das medidas de controle e profilaxia da doença, e por fim, a eliminação dos positivos, como medida de defesa sanitária animal.

Em outro estudo realizado em região pantanosa, Silva et al. (2001) verificaram uma taxa de prevalência de $18,2 \%$ em animais de serviço, utilizados na lida de gado na região do pantanal sul-mato-grossense. Esta alta taxa de prevalência está relacionada a animais de trabalho, ou seja, equinos de criação mais rústica, de idade mais avançada, muitas vezes, sem preocupação sanitária por parte dos produtores.

Também foi encontrada baixa prevalência de AIE em haras no estado de Minas Gerais $(0,44 \%)$. Observa-se que há cumprimento mais rigoroso da legislação quando se trata de animais com alto valor zootécnico, ou seja, controle sorológico periódico em dia e abate de animais positivos ao teste de IDGA. Dessa forma, é possível manter propriedades livres da doença, uma vez que cavalos de haras geralmente viajam mais e são submetidos aos controles oficiais com maior frequência do que os animais de serviço (ALMEIDA et al., 2017).

Barzoni et al. (2018) afirmam que levantamentos sobre a real situação da prevalência de AIE no Brasil são dificultados pelo fato de que os dados levantados até então, referem-se apenas aos testes realizados naqueles animais que estão com resultado negativo para emissão da Guia de Trânsito Animal (GTA) ou em casos de levantamento para certificação de propriedades pelo órgão oficial. $O$ fato de não existirem dados epidemiológicos dos animais utilizados para trabalho, que constituem a maior parte do plantel de equídeos brasileiro, pode ser considerado um entrave para os estudos da real situação da enfermidade.

\section{Influenza Equina (IE):}

A Influenza equina (IE) trata-se de uma infecção respiratória que acomete equídeos (cavalos, jumentos, mulas e zebras) em todo o mundo. Além disso, é uma doença de relevância econômica, visto que é altamente contagiosa, podendo afetar a performance dos animais acometidos, levando até mesmo a morte (SACK et al., 2019).

A enfermidade é causada por dois subtipos diferentes do vírus influenza tipo $A$ (H7N7, H3N8), da família Orthomyxoviridae. Trata-se de um vírus de RNA com polaridade negativa e envelopada, no qual o envelope possui glicoproteínas, como a hemaglutinina e a neuraminidase. Os dois subtipos do vírus podem ser diferenciados através de seus antígenos (KUMAR et al., 2016). 
$\mathrm{O}$ vírus do subtipo H3N8 dissemina-se com maior facilidade em animais mais susceptíveis e é conhecido por causar doença clínica grave em equídeos (VIRMANI et al., 2010). Os vírus se replicam nas células epiteliais do trato respiratório superior (traqueia e brônquios) levando a destruição do epitélio ciliar e consequentemente, estase do muco, o que pode causar uma pneumonia bacteriana secundária. Produzem também sinais respiratórios que variam em severidade e duração de acordo com a virulência da amostra viral, o manejo, as condições ambientais e as defesas do hospedeiro. A tosse contínua, que é uma característica importante da doença, serve para liberar grandes quantidades de vírus no ambiente (SACK et al., 2017).

A transmissão do vírus ocorre mediante contato direto dos animais, aerossóis, fômites, e em situações de aglomerações como em eventos equestres, na ocasião do transporte por longas distâncias ou confinados em locais com pouca ventilação. $O$ transporte e a aglomeração dos animais em locais escuros, pouco ventilados, favorecem a ocorrência da enfermidade. A disseminação do vírus pode ser intensificada após o evento, uma vez que a principal via de transmissão é por aerossóis, e a principal via de infecção é a respiratória, levando a um grande impacto em relação ao controle da infecção pelo vírus da gripe (CULLINANE et al., 2010).

Os sinais clínicos da infecção consistem em febre, anorexia, letargia, secreção nasal e tosse. A pirexia é frequentemente o primeiro sintoma presente (LANDOLT, et al., 2007).

O diagnóstico pode ocorrer de forma presuntiva, levando em consideração os sinais clínicos apresentados pelos animais. No entanto, como método de diagnóstico definitivo, pode ser citado o diagnóstico direto, no qual há a identificação do agente a partir de swabs nasais ou nasofaringeais ou de lavados traqueais. O diagnóstico indireto utiliza a análise das amostras de soro do animal suspeito em busca de evidências da ação do vírus no organismo. Além destes métodos, a identificação do agente também pode ser realizada através de testes de qRT-PCR (Real-Time Quantitative Reverse Transcription PCR), RT-PCR (Reverse Transcription Polymerase Chain Reaction), ensaio da neuraminidase e teste de inibição da neuraminidase, imunofluorescência direta, ELISA, isolamento viral em ovos embrionados de galinha ou em células MDCK (Madin- Darby Caninne Kidney) (OIE, 2019). O teste de hemaglutinação viral (HA) seguido do teste de inibição da hemaglutinação $(\mathrm{HI})$ também pode ser citado e é realizado para identificar o tipo de proteína HA do vírus (OIE, 2019).

A estratégia de prevenção e controle da influenza equina preconizada é a vacinação anual ou semestral. Esta se baseia na produção de anticorpos contra as glicoproteínas de superfície, especialmente HA (DALY et al., 2011).

Através da compilação dos dados sorológicos e dados virológicos, é possível concluir que o H3N8 e os vírus da gripe equina H7N7 circulam na população equina no Brasil. O número de estudos sobre a caracterização de EIV no Brasil é muito pequeno, exceto em 2012 quando ocorreu um surto no País (FAVARO et al., 2016).

\section{Mormo}

Doença infectocontagiosa de curso agudo ou crônico, que acomete principalmente os equídeos, mas pode acometer também carnívoros, o homem e, eventualmente, pequenos ruminantes. O mormo é causado pelo agente etiológico Burkholderia mallei (DITTMANN et al., 2015), um bacilo gram-negativo intracelular 
obrigatório, imóvel, é naturalmente resistente a antibióticos múltiplos e há grande preocupação com seu potencial uso como arma biológica, o que torna de suma importância para o desenvolvimento de uma vacina contra B. mallei (BAKER et al., 2017).

Trata-se de uma doença zoonótica rara em humanos, porém, altamente contagiosa, que quando os acomete, geralmente é fatal (BAKER, et al., 2017; FERRAREZl et al., 2020). Acredita-se que a enfermidade foi introduzida no Brasil em 1811, a partir da aquisição de animais infectados vindos da Europa. O primeiro local brasileiro com registros da doença foi a Ilha de Marajó, no estado do Pará, na qual foram relatados surtos epidêmicos em equídeos, e até mesmo acometendo seres humanos (RIBEIRO, 2016).

Dittmann et al. (2015) tratam a doença como re-emergente mediante relatos sobre o aumento do número de surtos que elevaram a taxa de mortalidade em equídeos. A doença foi erradicada de grandes áreas do mundo ocidental no início do século XX, porém, Kettle e Wernery, (2016) relatam que nos últimos 10-20 anos, reemergiu e ressurgiu em locais em que anteriormente era desconhecido ou havia sido erradicado.

Said et al. (2016) afirmam que a doença é transmitida a partir da invasão das bactérias nas vias nasal, oral, mucosa das conjuntivas e até mesmo através de soluções de continuidade presente na pele dos animais. Assim sendo, a via respiratória pode ser citada como a principal via de eliminação da bactéria. Além disso, a contaminação de alimentos, água e fômites e também animais com infecção crônica e portadores assintomáticos são considerados de grande importância na transmissão da doença entre animais doentes e sadios. Para os humanos, a doença pode ser transmitida a partir do contato com material contaminado e também a partir do contato com secreções contaminadas de animais doentes.

Embora a doença possa ocorrer em quadros crônicos ou agudos, comumente encontram-se relatos de que a forma crônica ocorra em equinos e a forma aguda ocorra frequentemente em muares e asininos, levando os mesmos à morte em cerca de quatro a sete dias, além disso, podem apresentar quadros de febre alta e anorexia, úlceras do septo nasal, secreção muco-purulenta com possível evolução para secreção hemorrágica (SAID et al., 2016).

Os equinos acometidos pela manifestação crônica da doença vão apresentar quadros de tosse acompanhada de epistaxe e dispneia. Além disso, irão apresentar lesões no septo nasal, secreção nasal purulenta e congestão, o que mostra que aqueles animais acometidos por essa forma da doença podem apresentar vários sinais clínicos, a depender da via de infecção (SAID et al., 2016).

A bactéria geralmente penetra no organismo através de feridas cutâneas, olhos, boca e nariz, ocasionando o aparecimento inicial de febre, mal estar, indícios de sinais de pneumonia, pústulas e abcessos. Pode se considerar que a $B$. mallei afeta os sistemas linfático e respiratório levando a altas taxas de mortalidade e morbidade, e pode assumir as formas nasal, pulmonar e cutânea, dependendo de onde está localizada a lesão inicial, podendo os animais apresentarem as três formas ou apenas uma. Nos animais infectados, formam-se lesões primárias na faringe, estendendo-se para o sistema linfático onde causa lesões nodulares. Metástases são encontradas nos pulmões, baço, fígado e pele. No septo nasal, pode ocorrer lesões primárias de origem 
hematógena ou secundária a um foco pulmonar (DITTMANN et al., 2015).

O mormo é uma das doenças animais de declaração obrigatória para a Organização Mundial de Saúde Animal (OIE), devido ao impacto econômico sobre o comércio internacional de animais e seus subprodutos (OIE, 2021). De acordo com a Instrução Normativa № 6, de 16 de janeiro de 2018 do Ministério da Agricultura Pecuária de Abastecimento (MAPA), qualquer caso suspeito deve ser notificado ao serviço veterinário oficial, sendo obrigatório para qualquer cidadão, assim como aos profissionais que trabalham na área de ensino, pesquisa ou diagnóstico em saúde animal. Não há nenhuma vacina contra a infecção da $B$. mallei e o tratamento não é recomendado, sendo obrigatória a eutanásia dos animais positivos (BRASIL, 2018b).

O diagnóstico clínico baseia-se primeiramente na identificação das lesões descritas. As úlceras nasais são características e as suspeitas devem ser notificadas ao serviço de Defesa Sanitária Animal (RIBEIRO, 2016). Entre os testes laboratoriais disponíveis, a legislação brasileira e a OIE recomendam o teste da fixação de complemento (FC), como teste sorológico, e o teste da maleína (reação imunoalérgica) para fins de trânsito, em caso de animais reagentes à prova de FC. O teste sorológico possui alta sensibilidade e boa especificidade (MAPA, 2016).

A prevenção da doença em seres humanos deve ocorrer de acordo com as instruções preconizadas pelo Ministério da Agricultura Pecuária e Abastecimento (BRASIL, 2018b), que prioriza o manejo ambiental e controle sanitário dos animais, o que envolve a eliminação de animais com diagnóstico laboratorial positivo.

Uma das formas de prevenção da enfermidade para os animais é a realização da sorologia antes do transporte dos animais. Mediante o resultado negativo na fixação de complemento (validade de 60 dias), os animais podem circular livremente, representando a importância da fiscalização de transito interestadual (BRASIL, 2018b). Além disso, preconiza-se sempre a quarentena para aqueles animais recém chegados na propriedade, além da interdição da mesma quando houverem casos positivos, realizando, limpeza e desinfecção das áreas de foco, incineração e destino apropriado de carcaças de animais infectados e eutanasiados, desinfecção de veículos e equipamentos (cabrestos, arreios e outros), eliminação de cochos coletivos, aquisição de animais de áreas livres da doença e com diagnóstico laboratorial negativo, e utilização de equipamentos de proteção individual (MAPA, 2016).

\section{Encefalomielites Equina do Leste, Oeste e Venezuelana}

A encefalomielite é uma das infecções mais comuns que acometem o sistema nervoso central (SNC) de equinos em todo o mundo. A encefalomielite viral dos equinos pode ser ocasionada por três diferentes tipos de RNA vírus da família Togaviridae, do gênero Alphavirus: Leste (EEL), Oeste (EEO) e Venezuelana (EEV) responsáveis por causarem quadros neurológicos extremamente graves tanto em humanos quanto em equinos. É importante ressaltar que trata-se de uma doença de potencial zoonótico de alta letalidade (BARBA et al., 2019).

De acordo com Barba et al. (2019) a transmissão ocorre através de mosquitos e aves selvagens, principais hospedeiros do reservatório. Os equinos são reservatórios chave para EEV, uma vez que desenvolvem alta viremia, podendo atuar como fonte de infecção para mosquitos. No entanto, de acordo com Zacks e Paessler, (2010), os agentes etiológicos podem ser também transmitidos através de aerossóis. 
Os sinais clínicos variam de acordo com o agente etiológico e sua virulência. No entanto, as três cepas virais causam sinais clínicos parecidos como quadros febris, diminuição de reflexos, anormalidade ao andar (geralmente em círculos) ou até falta de equilíbrio e movimentos de pedalagem, paralisia e morte que pode ocorrer também de forma súbita (KUMAR et al., 2018), apatia, sonolência, ataxia, convulsões, dificuldades para urinar e defecar, paralisia facial e outros sintomas não neurológicos (BARBA et al., 2019).

O diagnóstico pode ser direto ou indireto. O diagnóstico direto será realizado de forma que amostras dos tecidos do sistema nervoso central sejam enviadas com agilidade (alta sensibilidade a variações de temperatura e ph) para o laboratório. Caso o animal esteja em fase aguda, podem ser enviadas amostras de sangue e líquido cefalorraquidiano para tentativa de isolamento, realizado em camundongos ou culturas de células. Além disso, também podem ser realizados testes de RT-PCR e sequenciamento genético. Já o diagnóstico indireto ocorre a partir de testes sorológicos a partir de amostras de soro dos animais em fase aguda e de recuperação, apresentando resultados bastante confiáveis. Serão utilizados testes de ELISA, neutralização, inibição de hemaglutinação, fixação do complemento (GRIFFIN, 2001).

Sousa et al. (2015) demonstram a presença do vírus da EEL circulante no Brasil. Estes achados reforçam a importância de se manter estudos epidemiológicos e clínicopatológicos em todo o País para que o controle e a prevenção dessas enfermidades sejam efetivamente realizados pelos órgãos oficiais de vigilância (SOUSA et al., 2015).

Não há tratamentos antivirais específicos, sendo realizada uma terapia de suporte. O controle inclui evitar o pastejo dos equídeos em áreas alagadiças, pois estes locais predispõem a proliferação dos vetores, vacinar os animais anualmente, utilizar agentes químicos em reservatórios de água para controlar a deposição de ovos e eliminar criadouros dos mosquitos (KUMAR et al., 2018).

\section{CONCLUSÃO}

Diante do crescimento da equideocultura brasileira, torna-se de suma importância o conhecimento das doenças infectocontagiosas de maior incidência no País, a fim de se estabelecerem medidas eficazes de controle e prevenção que visem diminuir os impactos econômicos gerados por estas. Algumas doenças, como por exemplo, a anemia infecciosa equina e o mormo exigem o sacrifício dos animais positivos, pois não são tratáveis e também não possuem vacinas, outras como no caso das encefalomielites e influenza equina, tratam-se de zoonoses de grande importância, e todas estas doenças se disseminam facilmente pelo plantel, o que acarreta grande prejuízo aos criadores. Portanto, além da adoção de medidas profiláticas e de controle, é de extrema relevância a fiscalização e notificação destas enfermidades aos órgãos responsáveis, visando um controle epidemiológico da situação das mesmas e também a adoção de medidas educativas aos criadores de forma eficaz. Além disso, é importante salientar que a partir do levantamento epidemiológico da situação de tais enfermidades, é possível observar a importância de estudos, tanto da iniciativa privada quanto da iniciativa pública, referentes à vacinação e tratamento destas doenças. 


\section{REFERÊNCIAS}

ALMEIDA, V.M.A.; OLIVEIRA, C.H.S.; FIORILLO, K.S.; MARTINS, M.F.; LEITE, R.C.; REIS, J.K.P.; GONÇALVES, V.S.P. Prevalence of equine infectious anemia in stud farms in Minas Gerais, Brazil. Semina: Ciências Agrárias, v. 38, n. 3, p. 1335-1346, 2017.

Disponível

em:

http://www.uel.br/revistas/uel/index.php/semagrarias/article/view/23982 DOI: http://dx.doi.org/10.5433/1679-0359.2017v38n3p1335

BAKER, S.M.; DAVITT, C.J.H.; MOTYKA, N.; KIKENDALL, N.L.; RUSSELL-LODRIGUE, K.; ROY, C.J.; MORICl, L.A. A Burkholderia pseudomallei Outer Membrane Vesicle Vaccine Provides Cross Protection against Inhalational Glanders in Mice and NonHuman Primates. Vaccines, v. 5, n. 4, p. 49-66, 2017. Disponível em: https://www.mdpi.com/2076-393X/5/4/49 DOI: https://doi.org/10.3390/vaccines5040049

BARBA, M.; FAIRBANKS, E.L.; DALY, J.M. Equine viral encephalitis: prevalence, impact, and management strategies. Veterinary Medicine: Research and Reports, v. 10, $\quad$ p. $\quad 99-110, \quad 2019 . \quad$ Disponível em: https://www.ncbi.nlm.nih.gov/pmc/articles/PMC6689664/pdf/vmrr-10-99.pdf DOI: 10.2147/VMRR.S168227

BARZONI, C.S.; NOGUEIRA, D.M.P.; MARQUES, G.D.; DIELH, G.N.; PELLEGRINI, D.C.P.; BRUM, M.C.S. Equine infectious anemia in the western region of Rio Grande do Sul, Brasil. Ciência Rural. v. 48, n. 6, 2018. Disponível em: https://www.scielo.br/scielo.php?script=sci_arttext\&pid=S0103-84782018000600451

BRASIL- Instrução normativa no 52, de 26 de novembro de 2018. Anexo - Normas para credenciamento e monitoramento de laboratórios de diagnóstico de anemia infecciosa equina. Diário oficial da República Federativa do Brasil, Secretaria de Defesa Agropecuária, Brasília, DF, 27 nov. 2018. Seção 1, ํo. 227, p.9. 2018a.

BRASIL- Instrução normativa no 6, de 6 de janeiro de 2018. Aprova as Diretrizes Gerais para Prevenção, Controle e Erradicação do Mormo no Território Nacional, no âmbito do Programa Nacional de Sanidade de dos Equídeos (PNSE). 2018b. Disponível em: http://www.cidasc.sc.gov.br/defesasanitariaanimal/files/2018/01/INMORMO-06.2018.pdf

BRASIL. Ministério da Agricultura, Pecuária e Abastecimento. Manual de Legislação Programas Nacionais de Saúde Animal do Brasil. Secretaria de Defesa Agropecuária. Departamento de Saúde Animal. Brasília, DF, 2009.

CILO, N. Equinocultura movimentou $\mathrm{R} \$ 16,5$ bi em 2018. Jornal Estado de Minas, $2019 . \quad$ Disponível em: https://www.em.com.br/app/noticia/economia/2019/03/22/internas_economia,1040030/e quinocultura-movimentou-r-16-5-bi-em-2018.shtml Acesso em: 15 jan. 2021.

CRAIGO, J. K.; MONTELARO, R. C. Equine Infectious Anemia Virus. In: MAHY, B. J. ENCICLOPÉDIA BIOSFERA, Centro Científico Conhecer - Jandaia-GO, v. 18 n. 35 ; p. 90 2021 
W.; VAN REGENMORTEL, M. H. V. Encyclopedia of Virology. Academic Press; n. 3, p. $167-174,2008$

CULLINANE, A.; ELTON, D.; MUMFORD, J. Equine influenza - surveillance and control. Influenza Other Respi Viruses, v. 4, n. 6, p. 339-344, 2010. Disponível em: https://onlinelibrary.wiley.com/doi/epdf/10.1111/j.1750-2659.2010.00176.x DOI: $10.1111 /$ j.1750-2659.2010.00176.x

CURSINO, A. E.; VILELA, A. P. P.; FRANCO-LUIZ, A. P. M.; et al. Equine infectious anemia virus in naturally infected horses from the Brazilian Pantanal. Archives of Virology, v.163, n.9, p.2385-2394, 2018. Disponível em: https://pubmed.ncbi.nlm.nih.gov/29752558/

CUTOLO, A.A.; GONÇALVES, V.L.M.; CORREZOLA, L.M.;GUNNEWIEK, M.F.K. Anemia infecciosa equina em equídeos de área urbana do município de Monte Mor, região metropolitana de Campinas, Estado de São Paulo, Brasil. Semina: Ciências Agrárias, v. 35, p. 1377-1382, 2014. Disponível em: http://www.uel.br/revistas/uel/index.php/semagrarias/article/viewFile/15266/14542 DOI: 10.5433/1679-0359.2014v35n3p1377

DALY, J.M.; MacRae, S.; NEWTON, J.R.; WATTRANG, E.; ELTON, D.M. Equine influenza: a review of an unpredictable virus. The Veterinary Journal, v. 189, n. 1, p. 714, $2011 . \quad$ Disponível em: https://www.sciencedirect.com/science/article/abs/pii/S1090023310002406?via\%3Dihub DOI: https://doi.org/10.1016/j.tvjl.2010.06.026

DITTMAN, L.R.; CARDOSO, T.O.; ROMÃO, F.G.; BARROS, L.D. Aspectos clínicopatológicos do mormo em equinos - revisão de literatura. Almanaque de Medicina Veterinária e Zootecnia, v. 1, p. 1-5, 2015. Disponível em: http://www.fio.edu.br/revistamv/arquivos/v1/ASPECTOS\%20CL\%C3\%8DNICOPATOL\%C3\%93GICOS\%20DO\%20MORMO\%20EM\%20EQUINOS\%20\%20REVIS\%C3\%830\%20DE\%20LITERATURA.pdf

DONG, J. B.; ZHU, W.; COOK, F. R.; et al. Identification of a novel equine infectious anemia virus field strain isolated from feral horses in southern Japan. Journal of General Virology, v.94, p.360-365, 2013. Disponível em: https://www.microbiologyresearch.org/docserver/fulltext/jgv/94/2/360_vir047498.pdf?exp ires $=1611235479 \&$ id=id\&accname=guest $\&$ checksum=F109F8DCEC1FFE968FDB4345 43B3BE6A DOI: 10.1099/vir.0.047498-0

FAVARO, P.F.; RICHTZENHAIN, L.J. A influenza equina no Brasil. Revista Brasileira de Pesquisa Veterinária e Zootecnia, v. 53, n. 2, p. 117-126, 2016. Disponível em: https://www.revistas.usp.br/bjvras/article/view/102897 https://doi.org/10.11606/issn.1678-4456.v53i2p117-126 
FERRAREZI, B.; BIFFI, B.M.; CAZAROTO, B.A.; KLAIN, P.; LIMA, S.R. Burkholderia mallei e o Mormo. Intellectus, v. 56, n. 1, 2020. Disponível em: http://www.revistaintellectus.com.br/ArtigosUpload/62.740.pdf

GRIFFIN, D.E. Alphaviruses In: Fields, B.N.; Knipe, D.M.; Howley, P.M. Fields Virology. Philadelphia: Lippincott Williams \& Wilkins; n. 4, 2001.

HARROLD, S. M.; COOK, S. J.; COOK, R. F.; et al. Tissue sites of persistent infection and active replication of equine infectious anemia virus during acute disease and asymptomatic infection in experimentally infected equids. Journal of virology, v.74, n.7, p.3112-3121, 2000. Disponível em: https://jvi.asm.org/content/74/7/3112 DOI: 10.1128 / jvi.74.7.3112-3121.2000

ISSEL, C.J.; COOK, R.F.; MEALEY, R.H.; HOROHOV, D.W. Equine infectious anemia in 2014: lives with it or eradicate it?. Veterinary Clinics of North America: Equine Practice, v. 30, n. 3, p. 561-577, 2014. Disponível em: https://www.sciencedirect.com/science/article/abs/pii/S0749073914000601?via\%3Dihub DOI: https://doi.org/10.1016/j.cveq.2014.08.002

ISSEL, C.J.; FOIL, L.D. Studies on equine infectious anemia vírus transmissioni by insects. Journal of American Veterinary Medical Association, v. 184, n. 3, p. 293297, 1984. Disponível em: https://pubmed.ncbi.nlm.nih.gov/6321420/

KETTLE, A.N.B.; WERNERY, U. Glanders and the risk of introduction through the international movement of horses. Equine Veterinary Journal, v. 48, n. 5, p. 654-658, 2016. Disponível em: https://beva.onlinelibrary.wiley.com/doi/epdf/10.1111/evj.12599 DOI: https://doi.org/10.1111/evj.12599

KUMAR, N.; BERA, B. C.; GREENBAUM, B. D.; BHATIA, S.; SOOD, R.; et al. Revelation of Influencing Factors in Overall Codon Usage Bias of Equine Influenza Viruses. Plos One, v. 11, n. 4, p.12-20, 2016. Disponível em: https://journals.plos.org/plosone/article?id=10.1371/journal.pone.0154376\#references DOI: http://dx.doi.org/10.1371/journal.pone.0154376

KUMAR, B.; MANUJA, A.; GULATI, BR.; VIRMANI, N.; TRIPATHI, B.N. Zoonotic Viral Diseases of Equines and Their Impact on Human and Animal Health. The Open Virology Journal, v. 12, p. 80-98, 2018. Disponível em: https://openvirologyjournal.com/VOLUME/12/PAGE/80/ DOI: $10.2174 / 1874357901812010080$

LANDOLT, G. A.; TOWNSEND, H. G. G.; LUNN, P. D. Equine Influenza Infection. In: SELLON, D. C.; LONG, M. T. Equine Infectious Diseases. Saunders-Elsevier, p. 124, 2007.

LEROUX, C.; COOK, R. F. Equine Infectious Anemia Virus. In: LIU, D. (Ed) Molecular detection of Animal Viral Pathogens. Boca Raton, CRC Press, n. 1, p. 177-189, 2016. DOI: https://doi.org/10.1201/b19719 
LANDOLT, G. A.; TOWNSEND, H. G. G.; LUNN, P. D. Equine Influenza Infection. In: SELLON, D. C.; LONG, M. T. Equine Infectious Diseases, Saunders-Elsevier, 2007. p.124.

MAPA. Ministério da Agricultura, Pecuária e Abastecimento. Revisão do Estudo do Complexo do Agronegócio do Cavalo. 2016. Disponível em: http://www.agricultura.gov.br/assuntos/camaras-setoriaistematicas/documentos/camaras-setoriais/equideocultura/anos-anteriores/revisao-doestudo-do-complexo-do-agronegocio-do-cavalo Acesso em: 15 dez, 2017.

MONTELARO, R. C.; BALL, J. M.; RUSHLOW, K. E. Equine retroviruses. In: LEVY (Ed). The Retroviridae. New York: Plenum Press, v. 2, Cap. 5, p.257-359, 1993.

NAVES, J. H. F. F.; OLIVEIRA, F. G.; BICALHO, J. M.; SANTOS, P. S.; Machado-deÁvila, R. A.; et al. Serological diagnosis of equine infectious anemia in horses, donkeys and mules using an ELISA with a gp45 synthetic peptide as antigen. Journal of Virological Methods, v. 266, p. 49-57, 2018. Disponível em: https://pubmed.ncbi.nlm.nih.gov/30576724

NOGUEIRA, M.F.; OLIVEIRA, J.M.; SANTOS, C.J.S.; PETZOLD, H.V.; AGUIAR, D.N.; JULIANO, R.S.; REIS, J.K.P.; ABREU, U.G.P. Equine infectious anemia in equids of Southern Pantanal, Brazil: seroprevalence and evaluation of the adoption of a control programme. Pesquisa Veterinária Brasileira, v. 37, n. 3, p. 227-233, 2017. Disponível em: https://www.scielo.br/scielo.php?pid=S0100736X2017000300227\&script=sci_arttext DOI: https://doi.org/10.1590/s0100$736 \times 2017000300005$

OAKS, J. L.; MCGUIRE, T. C.; ULIBARRI, C.; CRAWFORD, T.B. Equine infectious anemia virus is found in tissue macrophages during subclinical infection. Journal of virology, v. 72, n.9, p.7263-7269, 1998. Disponível em: https://www.ncbi.nlm.nih.gov/pmc/articles/PMC109949/

OLIVEIRA, F. G.; COOK, R. F.; NAVES, J. H. F.; OLIVEIRA, C.H.S.; DINIZ, R.S.; et al. Equine infectious anemia prevalence in feral donkeys from Northeast Brazil. Preventive Veterinary Medicine, v.140, p. 30-37, 2017. Disponível em: https://www.sciencedirect.com/science/article/abs/pii/S0167587717301666 DOI: https://doi.org/10.1016/j.prevetmed.2017.02.015

OIE. Organização Mundial de Saúde Animal. Enfermidades da lista da OIE. 2021. Disponível em: https://www.oie.int/en/animal-health-in-the-world/animaldiseases/Glanders/ Acesso em: 19 jan. 2021.

OIE. The Organization for animal Health. Gripe equine, 2017. Disponível em: http://www.oie.int/doc/ged/D14002.PDF Acesso em: 17 dez. 2017.

OIE. Organização Mundial de Saúde Animal. Listed disease, infectious and 
infectations in force in 2019. Paris: OIE, 2019. Disponível em: http://www.oie.int/animal-health-in-the-world/oie-listed-diseases-2019/. Acesso em: 25 de fevereiro de 2019.

RAVAZZOLO, A. P.; COSTA, U. M. Retroviridae. In: FLORES, E. F. (Org) Virologia Veterinária: virologia geral e doenças víricas. Revista, atualizada e amplificada. Santa Maria: Ed. da UFSM, n. 3, p. 809-837, 2017.

RIBEIRO, M.G. Mormo. In: MEGID, J.; RIBEIRO, M.G.; PAES, A.C. (Eds) Doenças infecciosas em animais e produção e de companhia. Roca, Rio de Janeiro, p.423435, 2016.

RICOTTI, S.; GARCIA, M.I.; VEAUTE, C.; BAILAT, A.; LUCCA, E.; COOK, R.F.; COOK, S.J.; SOUTULLO, A. Serologically silent, occult equine infectious anemia virus (EIAV) infections in horses. Veterinary Microbiology, v. 187, p. 41-49, 2016. Disponível em: https://pubmed.ncbi.nlm.nih.gov/27066707/ DOI: 10.1016 / j.vetmic.2016.03.007

SACK, A.; DARAMRAGCHAA, U.; CHULUUNBAATAR, M.; GONCHIGOO, B.; BZARTSEREN, B.; et al. Low Prevalence of Enzootic Equine Influenza Virus among Horses in Mongolia. Pathogens, v. 6, n. 4, p. 61-71, 2017. Disponível em: https://pubmed.ncbi.nlm.nih.gov/29189713/ DOI: 10.3390 / pathogens6040061

SACK, A.; CULLINANE, A.; DARAMRAGCHAA, U.; CHULUUNBAATAR, M.; GONCHIGOO, B.; et al. Virus da influenza equina - uma ameaça de doença reemergente e negligenciada. Doenças infecciosas emergentes, v. 25, n. 6, p. 11851191, 2019. Disponível em: https://wwwnc.cdc.gov/eid/article/25/6/16-1846_article

SAID, N.C.; NARDI JUNIOR, G.; DOMINGUES, P.F. Mormo em equinos e a biossegurança no agronegócio. Tekhne e Logos, v. 7, n. 3, 2016. Disponível em: http://revista.fatecbt.edu.br/index.php/tl/article/download/404/279

SELLON, D.C. Equine Infectious Anemia. Veterinary Clinics of North America Equine Practice, v. 9, n. 2, p. 321-336, 1993. Disponível em: https://pubmed.ncbi.nlm.nih.gov/8395326/

SILVA, M.L.; ALMEIDA, A.V.; NASCIMENTO, A.P.P.; SANTOS, J.D.; CASTRO, B.G. Estudo retrospectivo da anemia infecciosa equina na região médio-norte matogrossense, Brasil, 2006-2011. Revista Brasileira de Medicina Veterinária e Zootecnia, v. 14, n. 2, p. 79-85, 2016. Disponível em: https://www.revistamvezcrmvsp.com.br/index.php/recmvz/article/view/32123

SILVA, R.A.M.S.; ABREU, U.G.P.; BARROS, A.T.M. Anemia Infecciosa Equina: Epizootiologia, Prevenção e controle no Pantanal. Embrapa Pantanal, Circular Técnica $\mathbf{n}^{\circ} 29,2001$. 
SOUSA, S.K.H.; SONNE, L.; Sant'Ana, F.J.F.; REIS JR, J.L. Encefalomielite equina do leste no Distrito Federal e entorno. Acta Scientiae Veterinariae, v. 43, p. 1-6, 2015. Disponível em: https://www.redalyc.org/pdf/2890/289039763014.pdf

VIRMANI, N.; BERA, B.C.; SINGH, B.K.; SHANMUGASUNDARAM, K.; GULATI, B.R.; BARUA, S.; VAID, R.K.; GUPTA, A.K.; SINGH, R.K. Equine influenza outbreak in India (2008-09): Virus isolation, sero-epidemiology and phylogenetic analysis of HA gene. Veterinary Microbiology, v. 143, n. 2-4, p. 224-237, 2010.

ZACKS, M. A.; PAESSLER, S. Encephalitic alphaviruses. Veterinary Microbiology, v. $140, \quad$ n. $\quad 3-4, \quad$ p. 281-286, 2010. Disponível em: https://pubmed.ncbi.nlm.nih.gov/19775836/ DOI: 10.1016/j.vetmic.2009.08.023 